\title{
Infiltration versus Transversus Abdominis Plane Block for Post-Operative Analgesia in Patients Undergoing Elective Lower Segment Caesarean Section under Spinal Anaesthesia
}

\author{
Sentichuba Longchar ${ }^{1}$, Langpoklakpam Chaoba Singh², Saraswathi Ramakrishna ${ }^{3}$, \\ Ruben Ghatani ${ }^{4}$, Bijaya Chingtham ${ }^{5}$, Yangchen Bhutia ${ }^{6}$, Nongosal Kirha ${ }^{7}$ \\ ${ }^{1}$ Department of Anaesthesia, Faith Hospital, Dimapur, Nagaland, India. \\ 2, 3, 4, 5, 6,7 Department of Anaesthesia, Regional Institute of Medical Sciences, Imphal, Manipur, India.
}

\section{ABSTRACT}

\section{BACKGROUND}

Caesarean section is the most widely performed obstetric procedure. Even though epidural analgesia is the gold standard for lower abdominal surgery, search is on to have a good alternative where we want to avoid epidural analgesia. Transverses abdominis plane block is an emerging fascial plane block.

\section{METHODS}

A prospective randomized controlled study was conducted among 70 American Society of Anesthesiologists (ASA) I-II patients undergoing elective lower segment caesarean section under spinal anaesthesia. After written informed consent, the participants were divided into two groups randomly. After skin closure, bilateral TAP block was performed on Group T with $20 \mathrm{~mL}$ of $0.375 \%$ inj. ropivacaine on each side whereas surgical site local infiltration was given with same amount of drug. Postoperatively VAS was recorded at $0,2,4,6,8,10,12$ and $24 \mathrm{hr}$. Patient received intramuscular diclofenac $75 \mathrm{mg}$ on demand by the patient or when VAS score was more than 4 . The time taken for the first request of analgesia (T-rescue) was noted.

\section{RESULTS}

Time to first rescue analgesia was longer in group $\mathrm{T}$ (414.85 \pm 88.33 minutes) as compared to group I $(250.85 \pm 43.86$ minutes). Mean time for first request for analgesia (T-rescue) was significantly longer in the T group by 164 minutes ( $p$-value $=<.001)$ compared to I group. VAS score was significantly higher for infiltration group at $2 \mathrm{hr}$. and $4 \mathrm{hr}$. (1.97 \pm .70 and $3.77 \pm .54$, p-value $<.001)$. No side effects were recorded.

\section{CONCLUSIONS}

Patients who receive TAP block have longer postoperative pain free period. In our study we didn't find any major side effects of TAP block. In conclusion, TAP block was superior to surgical wound infiltration with respect to postoperative analgesia following caesarean delivery.

\section{KEY WORDS}

Transverses Abdominal Plane Block, Infiltration, Post-Operative Analgesia, Elective Lower Section Caesarean Section, Spinal Anaesthesia
Corresponding Author:

Dr. Langpoklakpam Chaoba Singh, Sangaiprou Mamang Leikai, Near Oil Pump, Airport Road, Imphal, Manipur -795001, India.

E-mail: drchaoba@gmail.com

DOI: $10.14260 /$ jemds/2020/804

How to Cite This Article:

Longchar S, Singh LC, Ramakrishna S, et al. Infiltration versus transversus abdominis plane block for post-operative analgesia in patients undergoing elective lower segment caesarean section under spinal anaesthesia. J Evolution Med Dent Sci 2020;9(48):36653669, DOI: $10.14260 /$ jemds/2020/804

Submission 24-08-2020,

Peer Review 18-10-2020,

Acceptance 24-10-2020,

Published 30-11-2020.

Copyright (C) 2020 Sentichuba Longchar et al. This is an open access article distributed under Creative Commons Attribution License [Attribution 4.0 International (CC $B Y 4.0)]$ 


\section{BACKGROUND}

Caesarean section is the most widely performed obstetric procedure, with an increasing prevalence, $8.5 \%$ (NFHS-3) to $17.2 \%$ (NFHS-4). ${ }^{1}$ Postoperative pain being one of the greatest concerns during and after abdominal surgery. ${ }^{2}$ Inadequate postoperative pain relief adversely affect ambulation, breastfeeding and even maternal bonding but providing effective analgesia improves the outcomes in terms of breastfeeding, infant weight gain and ambulation. ${ }^{3,4}$

Opioids are the gold standard choice of analgesia in the postoperative period, but it's used after caesarean section, is commonly associated with many undesirable side effects such as nausea, vomiting, sedation, urinary retention, respiratory depression and prolonged postoperative ileus. ${ }^{5-7}$ To overcome opioid-related adverse effects need arises for other modes of analgesia.

As part of multi-modal analgesia regimens, infiltration of local anaesthetic into the surgical site is commonly used. ${ }^{8}$ Studies have indicated that wound infiltration with local infiltration for post-caesarean section analgesia was effective in reducing opioid consumption. However, the use of local anaesthetic wound infiltration for alleviating post-operative pain has been studied in past decades with conflicting reports and scholars hold distinctly different views towards this issue. Also, most published studies indicated there was not a significant improvement in reduced pain scores. ${ }^{9-11}$

Over the last decade Transversus Abdominis Plane (TAP) block has gained popularity as an analgesic technique. Transversus abdominis plane block was formally documented by Rafi12 in 2001. TAP block involves injection of local anaesthetic into the fascial plane between internal oblique and transversus abdominis muscles, where the thoraco-lumbar nerves T6-L1 course innervating the anterior abdominal wall, with the help of ultrasound or anatomical landmark guidance. TAP block technique has been shown to be a safe and effective postoperative adjunct analgesia method in most of the lower abdominal surgeries. ${ }^{13,14}$ Advantages of TAP block include the avoidance of neuraxial analgesic techniques and their associated risk, reduction in post-operative opioid consumption and also known to increase the patients' satisfaction. 6,7

Thus, we conducted a study to compare the analgesic efficacy of infiltration of local anaesthesia versus transversus abdominis plane block in patients undergoing elective lower segment caesarean section under spinal anaesthesia, in terms of duration and quality of analgesia.

\section{METHODS}

Our study was a prospective, randomized, controlled trial conducted at Regional Institute of Medical Sciences, Imphal, Manipur, India, over a period of two years from August 2017 to September 2019. Approval from the Institutional Research Ethics Board was obtained, 70 adults patients aged $15-45$ years, ASA I-II scheduled to undergo elective lower segment caesarean section under spinal anaesthesia were included in the study. Patient refusal, patient with known hypersensitivity to any drug, history of alcoholism, neurologic, psychiatric or respiratory diseases, patient on medication with antidepressants, anticonvulsants or anti histamines within one week before the study, were excluded from the study.

\section{Procedure}

Pre-operative assessment was done a day before surgery. If no exclusion criteria was present, written informed consent was taken. The night before operation tablet ranitidine $150 \mathrm{mg}$ was given at bedtime. On arrival in the operation theatre, in the preoperative room Intra-Venous (IV) access was established. Monitoring of Non-Invasive Blood Pressure (NIBP), Heart Rate (HR), Oxygen Saturation ( $\left.\mathrm{SPO}_{2}\right)$, and Electro-Cardio-Gram (ECG) was started. All the patients received Ringer's lactate solution $10 \mathrm{~mL}$ per $\mathrm{kg}$ as pre loading solution within $30 \mathrm{~min}$ of spinal anaesthesia. Patient was put in left lateral position and spinal anaesthesia was given with inj. Bupivacaine (heavy) 0.5 $\% 2 \mathrm{~mL}$ after aseptic and anti-septic precaution.

The patients were allocated randomly with the help of computer generated numbers to 2 groups, Group I and Group $\mathrm{T}$ of 35 patients each. Group $\mathrm{T}$ patients received transversus abdominis plane block with $20 \mathrm{~mL} 0.375 \%$ ropivacaine per each side. Group I patients received infiltration at surgical incision with $40 \mathrm{~mL} 0.375 \%$ ropivacaine intra-operatively after lower segment caesarean section with the help of surgeon. At the end of surgery TAP block was performed. The transversus abdominis plane was identified using loss-of resistance technique by 20 -gauge $50 \mathrm{~mm}$ blunted needle. The triangle of Petit was palpated. The skin over the triangle of Petit was prepared with antiseptic solution. The needle was inserted perpendicular to the skin over the Petit's triangle. After two "pop" sensation, TAP plane was identified. The needle is stabilized and the prepared local anaesthetic solution was given after careful aspiration to exclude vascular puncture. Using an identical technique, TAP block was then performed on the opposite side. After completion of the surgical procedure and block, patients were transferred to the ward.

An investigator blinded to the allotment assessed pain severity by using visual analogue score (VAS) at 2, 4, 6, 8, 10, 12,24 hrs. $(0=$ no pain and $10=$ worst possible pain $) \cdot$ Rescue analgesia was given to patients on demand or when VAS is more than 4 in the form of Inj diclofenac $75 \mathrm{mg}$ IM.

The parameters were studied and compared in both the groups using time to first request for Inj diclofenac within 24 hrs. and VAS score at T-rescue. These assessments were performed in the ward within 24 hours after transversus abdominis plane blockade and local infiltration. The study ended after the time for first request of Inj diclofenac.

\section{Sample Size}

Based on a previous study by Sivapurapu et al $^{8}$ sample size is calculated using formula:

$$
\mathrm{N}=\frac{(\mathrm{U}+\mathrm{V}) 2\{(\mathrm{~S} 1) 2+(\mathrm{S} 2) 2\}}{(\mathrm{M} 1-\mathrm{M} 2) 2}
$$

Where,

- $\quad U=0.84$ (Power at $80 \%$ )

- $\quad \mathrm{V}=1.96$ (Confidence Interval at $95 \%$ )

- $\mathrm{S}=$ Standard Deviation; $\left(\mathrm{S}_{1}=1.98 ; \mathrm{S}_{2}=1.4\right)$

- $\mathrm{M}=$ Mean; $\left(\mathrm{M}_{1}=5.58 ; \mathrm{M}_{2}=4.12\right)$ 
Calculated sample size is 31 in each group but we took 35 patients in each group, in case of lost to follow-up.

\section{Statistical Analysis}

Data was entered in IBM SPSS Statistics 21 for Windows (IBM Corp. 1995, 2012). Duration of analgesia, time to first rescue analgesia (T-rescue) and VAS at T-rescue between two groups were compared by Independent student's test (t-test). A pvalue of $<0.05$ was taken as significant.

\section{RESULTS}

Seventy patients completed the study protocol. The demographic parameters of the two groups are shown in table 1.

\begin{tabular}{|cccc|}
\hline Characteristics & TAP & Infiltration & P-Value \\
$\begin{array}{c}\text { Age (Yr.) (Mean } \pm \\
\text { SD) }\end{array}$ & $30.40 \pm 4.55$ & $28.89 \pm 5.06$ & 0.193 \\
Weight (kg) & $54.91 \pm 2.81$ & $53.86 \pm 2.52$ & 0.102 \\
\hline \multicolumn{3}{|c|}{$\begin{array}{c}\text { Table 1. Socio-Demographic Characteristics } \\
\text { of the Patients in Each Group }(\mathbf{N}=35)\end{array}$} \\
\hline
\end{tabular}

The comparison of age between the groups using independent sample t-test shows that mean age of the patients in Group I and Group T were $28.89 \pm 5.06$ years and $30.40 \pm$ 4.55 years respectively and was comparable and the difference was not significant ( $p>0.193$ ). Comparison of weight between groups using independent sample t-test. Here the p-value is greater than the significance level 0.05 ; the difference in weight between groups was not significant. The table 1 shows that the weight was almost same in both group I ( $53.86 \pm 2.52$ $\mathrm{kgs})$ and group $\mathrm{T}(54.91 \pm 2.81 \mathrm{kgs})$, and thus weight did not have any effect on the present study.

\section{T-Rescue}

The comparison of time to first rescue analgesia between groups was studied here, using independent sample t-test. The difference in time to first rescue analgesia between groups was highly significant $(\mathrm{p}<0.01)$ as shown in table 2 .

\begin{tabular}{|cccc|}
\hline Group & $\begin{array}{c}\text { T-Rescue (min) } \\
\text { (Mean } \pm \text { SD) }\end{array}$ & Group & P-Value \\
\hline Group I & $250.85 \pm 43.86$ & Group I & $<.001$ \\
Group T & $414.85 \pm 88.33$ & Group T & \\
\hline \multicolumn{4}{|c|}{ Table 2. Comparison of Mean Time to T-Rescue (Minutes) } \\
between Groups
\end{tabular}

In figure 1 patients in group I requested for rescue analgesia between 165 minutes and 345 minutes. Mean time for t-rescue is $250.85 \pm 43.8 \mathrm{~min}$. Patients in group T requested for rescue analgesia between 300 minutes and 570 minutes. Mean time for t-rescue is $414.85 \pm 88.33 \mathrm{~min}$. It shows the time to first rescue analgesia was longer in group T (414.85 \pm 88.33 minutes) as compared to group I (250.85 \pm 43.86 minutes $)$. Thus, the TAP block group provides better post-operative analgesia as compared to infiltration group. The mean time for first request for analgesia (T-rescue) was significantly longer in the TAP group by 164 minutes $(\mathrm{p}$-value $=<.001)$ compared to infiltration group.

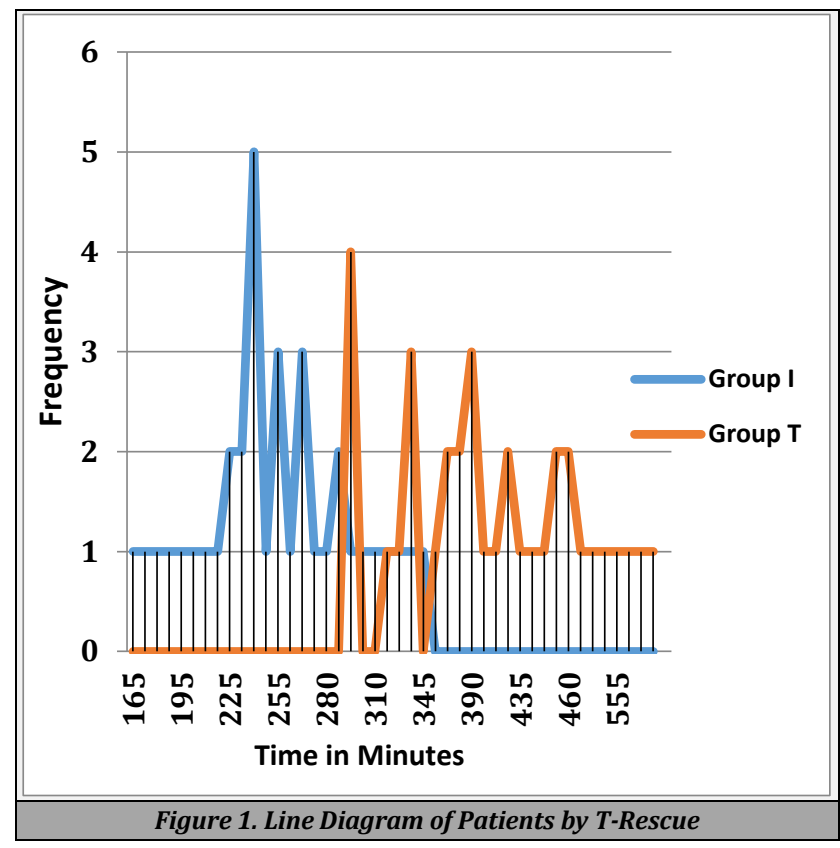

\section{VAS Score}

Comparison of VAS score at t-rescue between $\mathrm{T}$ and I groups was done using independent sample t-test. Table 3 shows that VAS score at t-rescue was significantly higher for infiltration group at $2 \mathrm{hr}$. and $4 \mathrm{hr}$. $(1.97 \pm .70$ and $3.77 \pm .54$, p-value < .001). Participants in Group I, mean time for t-rescue was $250.85 \pm 43.86$ mins with VAS score $4.00 \pm 00$ following $T$ rescue and were excluded from comparison with $\mathrm{T}$ group at 6 hours. For Group T, mean time for t-rescue was $414.85 \pm 88.33$ mins. In Group T, T-rescue was longer by $164 \pm 96.70$ mins in comparison to infiltration group, and this was statistically significant ( $p$-value < 0.001). VAS score was significantly higher for infiltration group at $2 \mathrm{hr}$. and $4 \mathrm{hr}$. than the T group $(\mathrm{p}<0.001)$.

\begin{tabular}{|cccc|}
\hline Time & \multicolumn{2}{c|}{$\begin{array}{c}\text { VAS Score at T-Rescue (Mean } \pm \text { SD) } \\
\text { Group I }\end{array}$} & P-Value \\
& $1.97 \pm .70$ & $.00 \pm .00$ & $<.001$ \\
\hline $2 \mathrm{~h}$ & $3.77 \pm .54$ & $1.71 \pm .71$ & $<.001$ \\
$4 \mathrm{~h}$ & $*$ & $3.00 \pm .93$ & \\
$6 \mathrm{~h}$ & $*$ & $3.50 \pm .83$ & \\
$8 \mathrm{~h}$ & $*$ & $4.00 \pm .00$ & \\
\hline $10 \mathrm{~h}$ & Table 3. Comparison of VAS Score at T-Rescue \\
between the Two Groups
\end{tabular}

\section{DISCUSSION}

Pain after caesarean delivery has certain peculiarities. Surgery related pain, frequently described as 'aching' in nature, is generally limited near the surgical site. The postoperative analgesia is beneficial because it is proven to cause decrease in the postoperative stress response, morbidity, and also helps in improved surgical outcome. To achieve these goals, a multimodal analgesic regimen is most likely used. However, the optimal components of a multimodal analgesic regimen continue to evolve. ${ }^{15}$ 
The mean age group for this study was $28.89 \pm 5.06$ years and $30.40 \pm 4.55$ years in the infiltration and TAP block group respectively, which is comparable to studies conducted by McMorrow RCN et al ${ }^{16}$ (spinal morphine $=33 \pm 4$ years, TAP block with local anaesthetic $=34 \pm 6$ years, TAP block with saline $=33 \pm 5$ years, spinal saline $=34 \pm 5$ years $)$, Nguyen NK et $\mathrm{al}^{17}$ (study group $=31.7 \pm 5.5$ years and control group $=$ $32.25 \pm 5.4$ years) and Puddy et al $^{18}$ (study group $=32 \pm 5.3$ years and control group $=33 \pm 5.7$ years).

Pratheeba et al ${ }^{19}$ in their analysis compared USG (UltraSono-Graphy) -guided TAP block using $2.5 \mathrm{mg} / \mathrm{kg}$ of $0.5 \%$ ropivacaine and Wound Site Infiltration (WSI) and assessed the efficacy of TAP block with ropivacaine for a period of 24 hours post-operatively in patients undergoing lower abdominal surgery. They found that those patients who received TAP block have lower post-operative VAS at $24 \mathrm{hr}$. and had significantly longer time (6 hours) for rescue analgesia $(p=0.001)$ when compared to patients who received WSI. Our study correlated well with the above study wherein we too observed that patients who underwent TAP block took significantly longer time to request for the first rescue analgesic, i.e. $414.85 \pm 88.33$ minutes when compared to patients who received Infiltration of surgical incision (250.85 \pm 43.86 minutes) and it is statistically significant ( $p=<0.001$ ).

Mankikar et $\mathrm{al}^{20}$ in their analysis compared USG-guided TAPB using $0.5 \%$ ropivacaine and placebo and assessed the efficacy of TAPB with ropivacaine for a period of $24 \mathrm{hr}$ postoperatively in patients undergoing Caesarean Section (CS). They put forth the results which showed that TAP block with ropivacaine compared with normal saline had reduced postoperative VAS at 24 hour and also increases the time for rescue analgesia. McDonnell et $\mathrm{al}^{19}$ also compared a placebo with TAP block and reported that TAP block provided superior analgesia until 48 hours.

Atim et $\mathrm{al}^{21}$ in their prospective research which was like our study evaluated the efficacy of ultrasound-guided TAP block and bupivacaine infiltration of the skin and subcutaneous tissue of the wound in patients undergoing hysterectomy. They found that lesser pain scores in TAP block group at the 6 hour and 24 hour and suggested that TAP block was more effective than infiltration at surgical site in postoperative pain management. Further, a review of infiltration of LA (Local Anaesthesia) subcutaneously at the surgical incision site in patients undergoing abdominal surgeries such as caesarean section, abdominal hysterectomy, and open cholecystectomy showed that this method is not very effective in reducing postoperative pain. ${ }^{22}$

Guo $Q$ et $\mathrm{al}^{23}$ in their systematic review and meta-analysis of nine studies, reported TAP block to have significantly lower dynamic pain score at 8 hours and 24 hours and wound site infiltration to have a limited short period of pain control. The effect of wound site infiltration was reported to reach the peak at 1 hour postoperatively and the effect decreases to the minimum by 8 hours. Similar to their findings, in our study, there was effective analgesia for the first four hours $(\mathrm{p}=<$ $0.001)$ with reduced VAS in the TAP block group (1.71 \pm .71$)$ as compared to Infiltration group ( $3.77 \pm .54)$, thus proving better analgesic efficacy of the TAP block in the early postoperative period. VAS score was significantly higher for infiltration group at 2 hours and 4 hours post-operatively in our study, which is consistent with the review done by Champaneria $\mathrm{R}$ et $\mathrm{al}^{24}$ where they concluded that TAP block improves early post-operative pain both at rest and on movement. A systematic review and meta-analysis of four randomized controlled trials done by $\mathrm{Yu} N$ et al ${ }^{14}$ also had similar findings of significantly lower pain scores 24 hours postoperatively in TAP block group. But the study also pointed out that the difference in pain scores differed by less than one point between TAP and local infiltration groups, suggesting that even though the difference is statistically different, the method may not be clinically significant as it may be challenging for a patient to tell the difference between a VAS score of 2 and 3. Thus, in according to them it is still uncertain that TAP provides better long-lasting clinical results but it provided better long-lasting analgesia at 24 hours after surgery.

Ultrasound for performing TAP block wasn't used by us as landmark technique had wider applicability and merit has been shown by previous studies. ${ }^{5}$ Petit's lumbar triangle is an easily identifiable with a fixed and palpable landmark. The TAP plane can easily be accessed via this triangle and local anaesthetic deposited into this plane, using the loss of resistance technique as we have described.

In our study we did not observe any post-operative side effects like nausea and vomiting, unlike the findings of Pratheeba et $\mathrm{al}^{19}$ where incidence of Post-Operative Nausea and Vomiting (PONV) was high (55.17\%) in group WSI compared to Group TAP (44.82\%). However, the difference was not statistically significant $(\mathrm{p}=0.516)$. Parallel findings done by Guo $Q$ et $\mathrm{al}^{23}$ in a review were observed where PONV incidence between the two groups was not statistically significant.

In conclusion, TAP block appeared to be superior to surgical wound infiltration with respect to postoperative analgesia following caesarean delivery.

\section{Limitations}

In our study, pain on movement was not assessed, as our primary aim was to compare the action of the two techniques. TAP block or wound infiltration involves only parietal component of pain. Movement causes both visceral and parietal pain and it would influence the duration of analgesia.

\section{CONCLUSIONS}

Patients who receive TAP block have longer postoperative pain free period. In our study we didn't find any major side effects of TAP block. In conclusion, TAP block was superior to surgical wound infiltration with respect to postoperative analgesia following caesarean delivery.

Data sharing statement provided by the authors is available with the full text of this article at jemds.com.

Financial or other competing interests: None.

Disclosure forms provided by the authors are available with the full text of this article at jemds.com.

\section{REFERENCES}

[1] Government of India. National family health survey - 4 . 
New Delhi: International Institute for population Sciences, Ministry of Health and Family Welfare India, 2016.

[2] Carvalho B, Cohen SE, Lipman SS, et al. Patient preferences for anesthesia outcomes associated with cesarean delivery. Anesth Analg 2005;101(4):1182-7.

[3] Leung AY. Postoperative pain management in obstetric anesthesia-new challenges and solutions. J Clin Anesth 2004;16(1):57-65.

[4] Hirose M, Hara Y, Hosokawa T, et al. The effect of postoperative analgesia with continuous epidural bupivacaine after cesarean section on the amount of breast feeding and infant weight gain. Anesth Analg 1996;82(6):1166-9.

[5] Li X, Zhou M, Shi X, et al. Local anaesthetic wound infiltration used for caesarean section pain relief: a a meta-analysis. Int J Clin Exp Med 2015;8(6):10213-24.

[6] Kehlet H, Rung GW, Callesen T. Postoperative opioid analgesia: time for reconsideration. J Clin Anesth 1996;8(6):441-5.

[7] Cali RL, Meade PG, Swanson MS, et al. Effect of morphine and incision length on bowel function after colectomy. Dis Colon Rectum 2000;43(2):163-8.

[8] Sivapurapu V, Vasudevan A, Gupta S, et al. Comparison of analgesic efficacy of transversus abdominis plane block with direct infiltration of local anaesthetic into surgical incision in lower abdominal gynaecological surgeries. J Anaesthesiol Clin Pharmacol 2013;29(1):71-5.

[9] Moiniche S, Dahl JB. Wound catheters for post-operative pain management: overture or finale? Acta Anaesthesiol Scand 2011;55(7):775-7.

[10] Rawal N, Borgeat A, Scott N. Wound catheters for postoperative pain management: overture or finale? Acta Anaesthesiol Scand 2012;56(3):395-6.

[11] Bamigboye AA, Hofmeyr GJ. Caesarean section wound infiltration with local anaesthesia for postoperative pain relief-any benefit? S Afr Med J 2010;100(5):313-9.

[12] Rafi AN. Abdominal field block: a new approach via the lumbar triangle. Anaesthesia 2001;56(10):1024-6.

[13] Rozen WM, Tran TMN, Ashton MW, et al. Refining the course of the thoracolumbar nerves: a new understanding of the innervation of the anterior abdominal wall. Clin Anat 2008;21(4):325-33.

[14] Yu N, Long X, Lujan-Hernanez JR, et al. Transversus abdominis-plane block versus local anaesthetic wound infiltration in lower abdominal surgery: a systematic review and meta-analysis of randomized controlled trials. BMC Anaesthesiol 2014;14(1):121.

[15] McDonnell JG, O'Donnell B, Curley G, et al. The analgesic efficacy of transversusabdominis plane block after abdominal surgery: a prospective randomized controlled trial. Anesth Analg 2007;104(1):193-7.

[16] McMorrow RCN, Mhuircheartaigh RJN, Ahmed KA, et al. Comparison of transversusabdominis plane block vs spinal morphine for pain relief after Caesarean section. Br J Anaesth 2011;106(5):706-12.

[17] Nguyen NK, Landais A, Barbaryan A, et al. Analgesic efficacy of pfannenstiel incision infiltration with ropivacaine $7.5 \mathrm{mg} / \mathrm{ml}$ for Caesarean section. Anesthesiol Res Pract 2010;2010:542375.

[18] Puddy E, Aluri S, Wrench I, et al. Ultrasound-guided transversusabdominis plane block does not improve analgesia after elective caesarean section when intrathecal diamorphine is used - a randomised doubleblind controlled trial. J Obstet Anaesth Critical Care 2012;2(2):98-102.

[19] Pratheeba N, Remadevi R, Raajesh IJ, et al. Comparison of postoperative analgesic efficacy of wound site infiltration and ultrasound-guided transversus abdominis plane block with $0.5 \%$ ropivacaine in lower abdominal surgeries under spinal anesthesia. Anesthesia Essays and Researches 2018;12(1):80-4.

[20] Mannikar MG, Sardesai SP, Ghodki PS. Ultrasoundguided transversus abdominis plane block for postoperative analgesia in patients undergoing caesarean section. Indian J Anaesth 2016;60(4):253-7.

[21] Atim A, Bilgin F, Kilickaya 0, et al. The efficacy of ultrasound guided transversus abdominis plane block in patients undergoing hysterectomy: a randomised double blind controlled study. Anaesth Intensive care 2011;39(4):630-4.

[22] Møiniche S, Mikkelsen S, Wetterslev J, et al. A qualitative systematic review of incisional local anaesthesia for postoperative pain relief after abdominal operations. $\mathrm{Br}$ J Anaesth 1998;81(3):377-83.

[23] Niraj G, Searle A, Mathews M, et al. Analgesic efficacy of ultrasound guided transversusabdominis plane block in patients undergoing open appendicectomy: a randomized double blind controlled study. Br J Anaesth 2009;103(4):601-5.

[24] Champaneria R, Shah L, Geoghegan J, et al. Analgesic effectiveness of transversusabdominis plane blocks after hysterectomy: a meta-analysis. Eur J Obstet \& Gynecol 2013;166(1):1-9. 